\title{
OPTIMIZACIJA ENERGETSKIH UŠTEDA U PROCESU PROIZVODNJE POTPLATA ZA CIPELE
}

\author{
Ivana Špelić', Alka Mihelić-Bogdanić ${ }^{1}$, Rajka Budin² \\ ${ }^{1 *}$ Sveučilište u Zagrebu Tekstilno-tehnološki fakultet, Prilaz baruna Filipovića 28 a, 10000 Zagreb, \\ Hrvatska
}

E-mail: ispelic@ttf.hr; amihelic@ttf.hr

${ }^{2}$ Sveučilište u Zagrebu, Fakultet kemijskog inženjerstva i tehnologije, Marulićev trg 19, 10000

Zagreb, Hrvatska

E-mail: rbudin@fkit.hr

Izvorni znanstveni rad

UDK: 66.011/.012:685.34.024.5

\section{Sažetak}

Od 1970-ih godina najpopularniji potplati cipela jesu EVA potplati, napravljeni od etilen vinil acetata, kopolimera koji se sastoji od etilena i vinil acetata. Duromeri i elastomeri (gume), među koje ubrajamo i EVA polimere, čine oko 30 $\%$ ukupne proizvodnje u tonama svih proizvedenih sintetskih polimera, pri čemu gume sintetskog podrijetla premašuju količinom proizvodnju guma prirodnog podrijetla. Imajući tu činjenicu na umu, energetske uštede u tvornicama proizvodnje gume iznimno su važne, a ovaj rad analizira potencijale energetskih ušteda u proizvodnji potplata za cipele napravljenih od etilen vinil acetata (EVA). EVA potplati za cipele jesu lagani, jednostavni za modeliranje, vodootporni i vlagootporni, jako elastični, amortiziraju udarce, dobri su toplinski izolatori, iznimno su otporni itd.

Energetske uštede povratom topline procesnoga kondenzata prezentirane su u procesu proizvodnje potplata za cipele. Povrat topline kondenzata rezultira smanjenom potrošnjom pojne vode, znatnim uštedama goriva potrebnog za proizvodnju pare i rezultiraju smanjenom potrošnjom kemikalija potrebnih u proizvodnom procesu. Povrat vreloga procesnoga kondenzata u kotao rezultira smanjenjem potrošnje nafte $14,9 \%$. Također se smanjuje toplinsko zagađenje 95,3 \%, dok se volumen ispušnih plinova smanjuje od $17,11 \mathrm{~m}_{\mathrm{FG}}^{3} / \mathrm{kg}_{\mathrm{NEC}}$ do $14,57 \mathrm{~m}_{\mathrm{FG}}^{3} / \mathrm{kg}_{\mathrm{NEC}}$ ili $14,8 \%$. Ovakav sustav omogućuje istodobnu uštedu nafte i smanjenje toplinskog zagađenja. Usporedbom procesa $s$ povratom topline dimnih plinova u odnosu prema procesu bez povratka topline dimnih plinova, pokazuje uštede od $18,76 \%$, uz smanjenje temperature dimnih plinova sa $221^{\circ} \mathrm{C}$ na $137,39^{\circ} \mathrm{C}$, pri čemu se volumen dimnih plinova smanjuje na $13,90 \mathrm{~m}_{\mathrm{FG}}^{3} / \mathrm{kg}_{\mathrm{P}}$.

\section{Ključne riječi}

energetske uštede; povrat topline kondenzata; proizvodnja potplata za cipele, etilen vinil acetat (EVA), smanjenje toplinskog zagađenja

\section{UVOD}

Prošlo stoljeće obilježeno je pojavom novih plastičnih pjena, a na svjetskom su tržištu, između ostaloga, predstavljene i nove duromerne termoreaktivne pjene. Duromerne termoreaktivne pjene, u koje spadaju i prirodne i sintetske gume, nemaju termoplastična svojstva i proizvode se istodobnim stvaranjem polimera uz generaciju plina. Općenito, bilo koja reakcija formiranja polimera može se upotrebljavati za pripremu pjena. Prva proizvodnja gume počela je u Prvom svjetskom ratu kad su uvedeni gumeni proizvodi od prirodne i sirove gume (Landrock, 1995.). Proizvodni materijali klasificiraju se kao metali, keramika, polimeri i kompoziti. Polimeri se nadalje klasificiraju kao termoplasti, termostati i elastomeri. Termoplastični polimeri mogu se podvrgnuti višestrukim ciklusima zagrijavanja i hlađenja bez bitnog mijenjanja molekularne strukture polimera. Uobičajeni termoplasti uključuju polietilen, polistiren, polivinilklorid i najlon (Groover, 2010.).
U proizvodnji i preradi gume sudjeluje nekoliko industrija, ali danas većina proizvedene gume na tržištu dolazi u obliku sintetskih guma, koje proizvodi petrokemijska industrija u tvornicama za preradu. Mnogi pjenasti gumeni dijelovi, kao što su potplati cipela, proizvode se modeliranjem u kalupima. Proizvodi sastavljeni od termoplastičnih polimera, koji uključuju etilen vinil acetat, polietilen, stiren blok kopolimer, butil gumu, poliamid, poliuretan i poliester, mogu se pripraviti kao vruća talina. Jednokomponentni termoplastični materijal stvrdnjava se iz taline nakon hlađenja na povišenim temperaturama (Groover, 2010.).

Potplati cipela donji su dio cipela u izravnom dodiru s podom. Danas se obično izrađuju od sintetičkih polimera kao što su poliizopren (IR), termoplastični poliuretan (TPU), poliuretanske pjene, etilen vinil acetat (EVA) ili polivinilklorid (PVC). Sintetski polimeri izrađeni su od raznih monomera na bazi nafte, a polimeri su 
postali glavni specijalizirani materijali za industriju obuće (Karkalića i sur., 2017.).

Od nastanka 1970-ih, najpopularniji potplati jesu potplati etilen vinil acetata (EVA) (Wang et al., 2012.; Fuss i sur., 2014.). Za industriju obuće proizvodi se mnogo artikala koji se koriste EVA smjesom (Lopes et al., 2015.). Etilen vinil acetat je kopolimer na bazi polimera koji se sastoji od etilena i vinil acetata (Shi et al., 2008.; Brito e Dias et al., 2018.), također nazvan ekspandirana guma ili pjenasta guma (sl. 1.). To je poliolefin s težinom etilena čiji postotak varira od 60 do 90 \% (Mike Chung, 2002.), dok postotak težine vinil acetata obično varira od 10 do $40 \%$ (Nautiyal, 2012.).

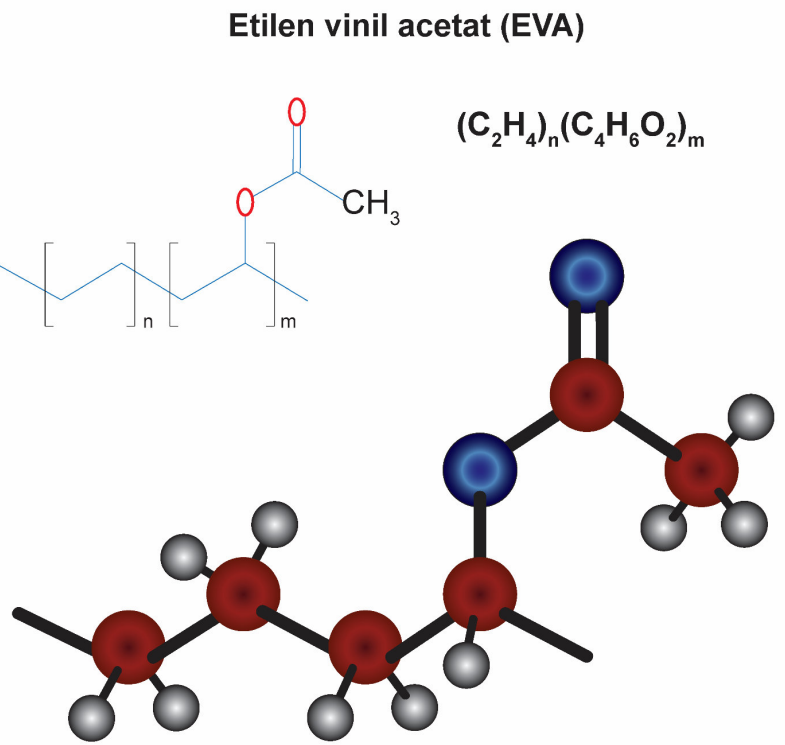

Slika 1. Strukturna formula etilen vinil acetata (EVA)

Etilen vinil acetat može se oblikovati ubrizgavanjem u kalupe kao i drugi poliolefinski elastomeri (nova klasa polimera, uglavnom kopolimeri etilen-butena ili etilenoktena, proizvedeni s pomoću metalokenskoga katalizatora) (Mike Chung, 2002.). EVA materijal ima dobru jasnoću, otpornost pri niskim temperaturama, otpornost na pukotine, vodootpornost, koja se postiže primjenom vrućih rastaljenih ljepila, otpornost na UV zračenje, sličnu mekoću, ekstremnu elastičnost i fleksibilnost kao i elastomerni materijali, ali se može obrađivati kao i drugi termoplastični materijali (Mike Chung, 2002.; Wang i sur., 2012.; Nautiyal, 2012.). Glavno obilježje EVA materijala jest znatna elastičnost koju karakterizira Youngov modul elastičnosti u rasponu od 15 do $80 \mathrm{MPa}$ (Brito e Dias et al., 2018.).

EVA je također poznata pod nazivima ekspandirana guma ili pjenasta guma. Materijal je poznat kao lagan i lak za oblikovanje, a popularan je jer je jeftiniji u usporedbi $s$ prirodnom gumom. Ostala popularna svojstva uključuju dobru otpornost na vodu i vlagu, visoku elastičnost, veliku mogućnost apsorpcije udara, dobra toplinska izolacijska svojstva, izdržljivost, otpornost na niske temperature, otpornost na pucanje, otpornost na vruće ljepilo i otpornost na UV zračenje (Jeng et al., 2012.). Potplati od etilen vinil acetata (EVA) poznati su po svojoj mekoći i fleksibilnosti (sl. 2.). Obrađuju se kao i drugi termoplastični materijali. EVA ima malo ili nimalo mirisa i konkurentna je gumenim i vinilnim proizvodima u mnogim električnim primjenama (Nautiyal, 2012.).

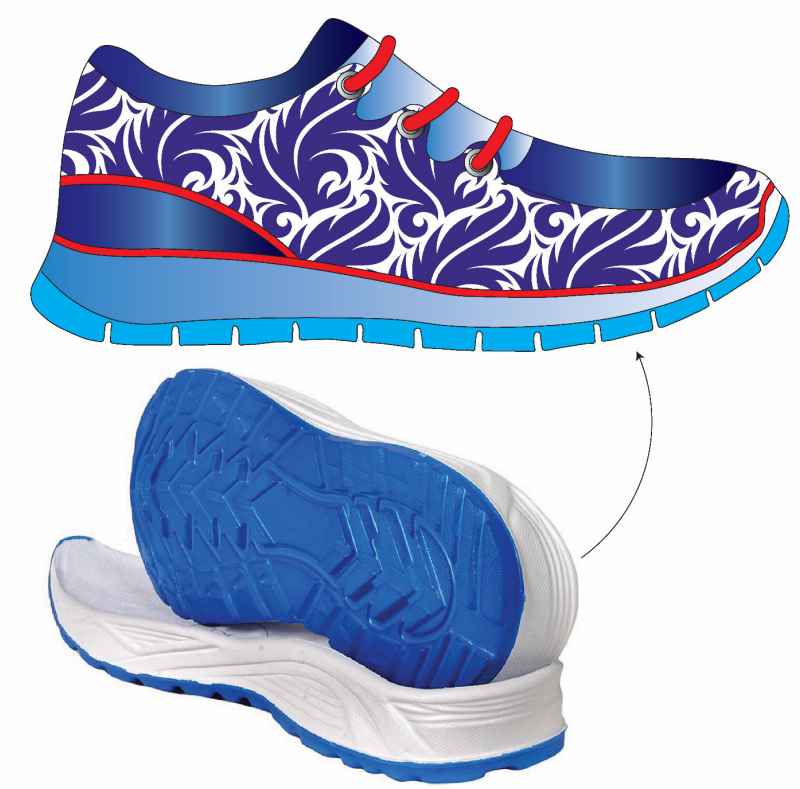

Slika 2. EVA potplati za tenisice

\subsection{PROCES OBLIKOVANJA POTPLATA CIPELA UBRIZGAVANJEM}

Glavni postupci oblikovanja gume jesu (Groover, 2010.):

1. oblikovanje prešanjem

2. transferno oblikovanje prešanjem

3. oblikovanje ubrizgavanjem (injekcijsko prešanje).

Postoje dva osnovna načina oblikovanja EVA potplata za cipele. Prvi način oblikovanja EVA potplata prešanjem (CMEVA) dobiva se punjenjem kalupa $s$ kuglicama EVA polimera, kako bi se postigao željeni oblik ili utiskivanjem bloka EVA pjene u metalni kalup. Toplina i tlak djeluju na kalup, prouzročujući rastapanje kuglica ili prouzročuju širenje EVA pjene, koja ispunjava šupljinu kalupa. Drugi je postupak oblikovanje ubrizgavanjem (injekcijsko prešanje). Izravno je ubrizgavanje proces ubrizgavanja grijanog termoplastičnog polimera u visoko plastičnom stanju pod visokim tlakom u šupljinu kalupa, kako bi se postigao željeni oblik. Procesom se proizvode zasebne komponente u oblik koji gotovo savršeno odgovara obliku kalupa. Uobičajeno vrijeme proizvodnog ciklusa u rasponu je od 10 do 30 sekundi (Groover, 2010.). Kad se materijal stvrdne u kalupu, on poprima željeni oblik i uklanja se iz kalupa. Injekcijsko prešanje vrlo je popularno zbog izostanka sirovinskih gubitaka jer je iskorištenje potpuno. Kalupi $s$ jednom šupljinom ili višestrukim šupljinama obično su izrađeni od čelika, aluminija ili nehrđajućeg čelika (López, 2014.). Injekcijsko prešanje ekonomski je isplativo samo u slučaju velikih proizvodnih količina. Kod injekcijskog 
prešanja gume postoji rizik prijevremenog stvrdnjavanja. Prednosti injekcijskog prešanja uključuju bolju dimenzijsku kontrolu, manje otpadaka i kraće vrijeme ciklusa. Zbog visokih troškova kalupa potrebne su velike proizvodne količine, kako bi se opravdalo injekcijsko prešanje (Groover, 2010.).

Stroj za injekcijsko prešanje sastoji se od (sl. 3.):

1. jedinica za ubrizgavanje plastike (slično ekstruderu)

2. jedinica za stezanje kalupa (preša).

Jedinica za brizganje plastike sastoji se od cijevi, koja se napaja lijevkom za dovod plastičnih kuglica. Unutar cijevi je povratna rotirajuća jedinica koja okreće i zagrijava polimer, a također ubrizgava rastaljenu plastiku u kalup. Jedinica za stezanje kalupa sadržava dvije ploče, fiksnu i pomičnu ploču, međusobno smještene u pravilnom odnosu, i drži kalup zatvoren tijekom ubrizgavanja primjenom sile stezanja, koja je dovoljna da se odupre sili ubrizgavanja i otvori i zatvori kalup (Groover, 2010.).

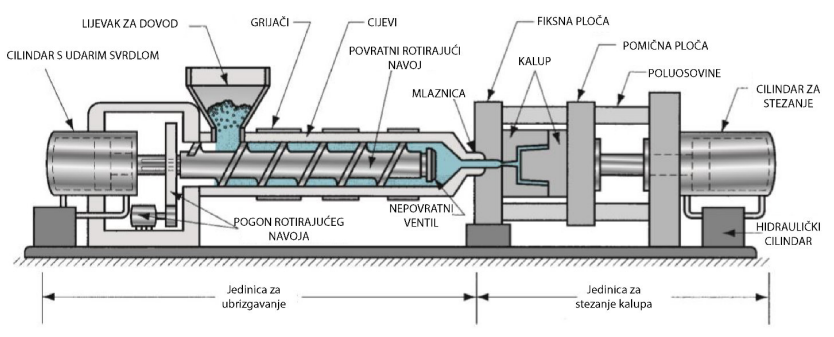

Slika 3. Stroj za injekcijsko prešanje

EVA mješavina dovodi se do ubrizgača koji može biti rotirajući ili višestruki jer je prosječni ciklus ubrizgavanja svakoga kalupa oko 7 minuta, tako da se strojem s više stanica može postići brža i učinkovitija proizvodnja (Ferreir et al., 2018.).

Koraci injekcijskog prešanja EVA (Ferreir et al., 2018.):

(a) Smjesa se dodaje u spremnik ubrizgača (injektor jedinica za ubrizgavanje).

(b) Volumen ubrizgavanja izračunava se i prilagođava prema kalupu.

(c) Materijal se zagrijava do $95^{\circ} \mathrm{C}$ i ubrizgava u kalup pri tlaku od oko 1200 bara.

(d) Kalup se zagrijava do $170^{\circ} \mathrm{C}$ da bi se aktivirao ekspander i uz istodobnu aktivaciju sredstava za umrežavanje elastomera.

(e) Kalup je zatvoren pri temperaturi od $170^{\circ} \mathrm{C}$ dok se ne stvore sve elastomerne veze, brzinom stvaranja sloja od oko $1,5 \mathrm{~min} / \mathrm{mm}$.

(f) Kalup se otvara i EVA potplat brzo izlazi iz šupljine te ekspandira.

Tehnički opis odabranog automatskog stroja za injekcijsko prešanje Eva pjene i godišnja energetska analiza prikazani su u tablici 1.
Tablica 1. Tehnički opis automatskog stroja za injekcijsko prešanje

\begin{tabular}{|c|c|}
\hline \multicolumn{2}{|c|}{ Tehnički opis } \\
\hline Radne stanice & 6 \\
\hline Sila stezanja $(\mathrm{kg})$ & $170000-230000$ \\
\hline Hod otvaranja kalupa (mm) & 350 \\
\hline Standardna debljina kalupa $(\mathrm{mm})$ & $100-210-230$ \\
\hline Veličina ploče kalupa (mm) & $2(290 * 550)$ \\
\hline Visina mlaznice za ubrizgavanje $(\mathrm{mm})$ & 60 \\
\hline Način grijanja & električno \\
\hline Snaga grijanja $(\mathrm{kW})$ & 8.04 \\
\hline \multicolumn{2}{|l|}{ Sustav ubrizgavanja } \\
\hline Ubrizgači (serija) & 2 \\
\hline Promjer vijka (mm) & $60 / 70$ \\
\hline Duljina/debljina omjer vijka & 23 \\
\hline Maksimalni kapacitet ubrizgavanja (cc) & $920-1100$ \\
\hline Injekcijski tlak & 1100 \\
\hline Brzina ubrizgavanja (cm/sek) & 10 \\
\hline Brzina okretanja vijka (okret u minuti) & $0-190$ \\
\hline Kontrola temperature (odjeljak) & 4 \\
\hline \multicolumn{2}{|l|}{ Potrošnja električne energije } \\
\hline Bačva za grijač (kW) & 12.1 \\
\hline Motor za pomicanje ubrizgača $(\mathrm{kW})$ & 1.5 \\
\hline Ploča za grijanje kalupa (kW) & 76.8 \\
\hline Hidraulički sustav (kW) (50 hz) & 40.5 \\
\hline Vakuumska pumpa (kW) & 2.2 \\
\hline Ventilator hlađenja cijevi (HP) & 1 \\
\hline Ukupna električna energija (kW) & $50 / 70 / 150$ \\
\hline Veličina spremnika za ulje (L) & 1000 \\
\hline Težina stroja $(\mathrm{kg})$ & 23800 \\
\hline Veličina stroja $(\mathrm{m})$ & $6.5 * 4.5 * 2.8$ \\
\hline Izlaz (par/dan) & 5000 \\
\hline Radno vrijeme (h/dan) & 8 \\
\hline Mjesečno radno vrijeme (dani/mjesec) & 25 \\
\hline
\end{tabular}

\subsection{ULAZNI PODATCI I ENERGETSKA ANALIZA TEHNOLOŠKOG PROCESA}

Potrošnja energije u proizvodnji cipela provodi se sa stopom $n=2500$ po smjeni (ili 5000 parova na dan ili 625 parova na sat). Ova tehnologija (sl. 2.) uključuje procese u miješalici, mlinu za zagrijavanje, cjedilu, rezaču, ekstruderu, hladnjaku itd. Postrojenje radi 8 sati na dan, 25 dana u mjesecu ili $\mathrm{T}=2400$ sati na godinu, tj. $\beta=27,4 \%$. Za takav osnovni proces potrebno je električne energije $e_{e l}=3,44 \mathrm{kWh}_{\mathrm{e}} \mathrm{n} / \mathrm{kg}$ proizvoda i suho zasićene pare (13 bar) mase $d_{s}=14,870 \quad \mathrm{~kg}_{\mathrm{s}} / \mathrm{kg}$ proizvoda. $U$ procesu se upotrebljava i voda mase $\mathrm{d}_{\mathrm{w}}=$ $4,57 \mathrm{~kg}_{\mathrm{w}} / \mathrm{kg}$ proizvoda (Mihelić-Bogdanić i Budin, 2008.). Suha zasićena para nastaje u kotlu $s$ učinkovitosti $\eta_{B}=80 \%$, izgaranjem nafte. 


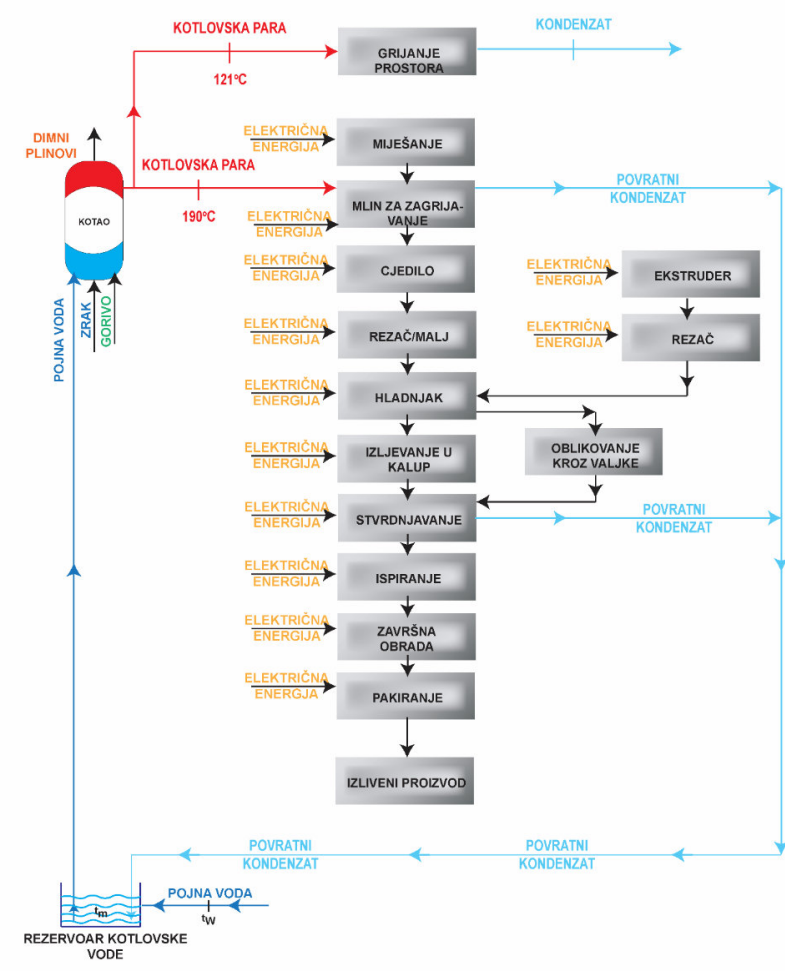

Slika 4. Dijagram toka proizvodnje potplata za cipele

Gorivo sastava (maseni postotci): C: $\mathrm{H}: \mathrm{N}: \mathrm{S}=85,3 \%$ : $11,6 \%: 0,6 \%: 2,5 \%$ izgara s koeficijentom suvišnog zraka $\alpha=1,25$. Dio zasićene pare $d_{S P}=14,170 \mathrm{~kg}_{s} / \mathrm{kg}_{\mathrm{P}}$ upotrebljava se za industrijski proces, a ostatak $\mathrm{d}_{\mathrm{SH}}=$ $0,7 \mathrm{~kg}_{\mathrm{s}} / \mathrm{kg}_{\mathrm{H}}$ za grijanje prostora. Donja toplinska vrijednost goriva jest $H_{L}=41268 \mathrm{~kJ} / \mathrm{kg}$ (MihelićBogdanić i Budin, 2008.). Pojna voda ulazi u kotao s temperaturom od $t_{B}=25^{\circ} \mathrm{C}$, a ukupni kondenzat $\mathrm{s}$ temperaturom $t_{C}=121^{\circ} \mathrm{C}$ izbacuje se $u$ okolinu. Zrak potreban za izgaranje goriva prelazi u ložište $\mathrm{s}$ temperaturom $t_{a}=25^{\circ} \mathrm{C}$, dok je temperatura ispušnih plinova $\mathrm{t}_{\mathrm{FG}}=221^{\circ} \mathrm{C}$.

Toplina predana kotlu jest:

$$
q_{s}=d_{s}\left(h_{s}-h_{B}\right)=14,870(2785-104,68)=39856,36
$$

gdje su $h_{S}$ i $h_{B}$ entalpije pare $i$ vode očitane iz termodinamičkih tablica (Mihelić-Bogdanić and Budin, 2008.).

Iz ovih podataka jedinična masa potrebe za naftom pomoću toplinske bilance jest:

$$
d_{F}=q_{S} / H_{L} \times \eta_{B}=39856,36 / 41268 \times 0,80=1,21
$$

Specifična potrošnja pare jest:

$$
d_{S P}=d_{s} / d_{F}=14,870 / 1,21=k_{s} / k_{F},
$$

a potrošnja ulja jest:

$$
d_{S F}=d_{F} / d_{S}=1,21 / 14,870=0,0814 \mathrm{~kg}_{\mathrm{F}} / \mathrm{kg}_{\mathrm{S}} \text {. }
$$

Uzimajući u obzir godišnje radno vrijeme $\mathrm{T}=2400$ sati $\mathrm{i}$ stopu proizvodnje potplata cipela $n=625$ parova, potrošnja goriva jest:

$$
D_{F Y}=d_{F} \times T \times n=1,21 \times 2400 \times 625=1,815 \times 10^{6} \mathrm{~kg}_{F} \text {. }
$$

Ukupni kondenzat $d_{C}$ iz procesa $d_{C P}=14,170 \mathrm{~kg}_{C} / \mathrm{kg}_{P}$ i iz prostora za zagrijavanje $d_{C H}=0,7 \mathrm{~kg}_{\mathrm{C}} / \mathrm{kg}_{\mathrm{H}} \mathrm{s}$ temperaturom $t_{c}=121^{\circ} \mathrm{C}$ izbacuje se $u$ okolinu (sl. 3.).

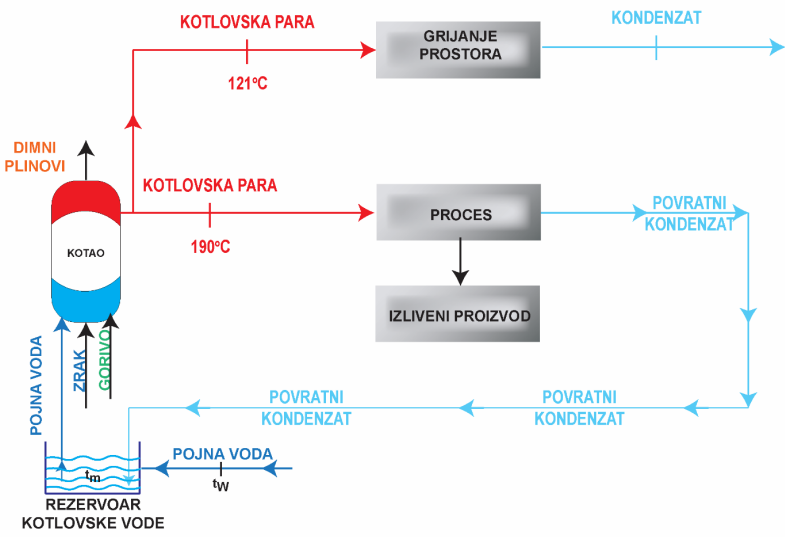

Slika 5. Povrat vrućega procesnoga kondenzata

Toplina kondenzata jest:

$$
\mathrm{q}_{\mathrm{C}}=\left(\mathrm{d}_{\mathrm{CP}}+\mathrm{d}_{\mathrm{CH}}\right) \mathrm{h}_{121}=(14,170+0,7) 507=7539,1
$$

Kako bi se poboljšala učinkovitost postupka (Lopez, 2014.), otpadni se kondenzat može primijeniti za predgrijavanje pojne vode.

\section{ANALIZE PROIZVODA IZGARANJA}

Produkti izgaranja goriva jesu plinovi (Eastop i McConkey, 1994.). Potpuno sagorijevanje goriva odvija se uz $25 \%$ zraka. Minimalni volumen kisika $V_{O 2 \text { min }} i$ stehiometrijski volumen zraka $\mathrm{V}_{\mathrm{a}}$ koji je potreban za izgaranje izražava se kao:

$\mathrm{V}_{\mathrm{O} 2 \min }=(22,4 / 12)\{\mathrm{C}+3[\mathrm{H}-(\mathrm{o}-\mathrm{s}) / 8]\}=2,26 \mathrm{~m}^{3}{ }_{\mathrm{O} 2} / \mathrm{kg}_{\mathrm{F}}$ $\mathrm{V}_{\mathrm{a}}=\mathrm{V}_{\mathrm{O} \text { min }} / 0,21=10,8 \mathrm{~m}_{\mathrm{a}}^{3} / \mathrm{kg}_{\mathrm{F}}$

Radi sigurnog potpunog sagorijevanja nafte uzet je koeficijent viška $\alpha=1,25$.

Stvarni volumen zraka jest:

$$
V_{a \alpha}=V_{a} \times \alpha=10,8 \times 1,25=13,5 \mathrm{~m}^{3} / \mathbf{k g}_{\mathrm{F}} \text {. }
$$

Ukupni volumen vlažnih dimnih plinova $\mathrm{V}_{\mathrm{FG}}$ sastoji se od ugljičnog dioksida, sumpornog dioksida, dušika, viška kisika i vodene pare:

$$
\mathrm{V}_{\mathrm{FG}}=\mathrm{V}_{\mathrm{CO} 2}+\mathrm{V}_{\mathrm{SO} 2}+\mathrm{V}_{\mathrm{N} 2}+\mathrm{V}_{\mathrm{O} 2}+\mathrm{V}_{\mathrm{H} 2 \mathrm{O}}
$$

Volumen svake komponente plina izračunava se $\mathrm{s}$ pomoću sljedećih izraza:

$$
\begin{gathered}
\mathrm{V}_{\mathrm{CO} 2}=\left(22,4 / 12 \mathrm{C}=(22,4 / 12) 0,853=1,592 \mathrm{~m}^{3} \mathrm{CO} / \mathrm{kg}_{\mathrm{F}}\right. \\
\mathrm{V}_{\mathrm{sO} 2}=(22,4 / 32) \mathrm{S}=(22,4 / 32) 0,025=0,0175 \\
\mathrm{~m}^{3}{ }_{\mathrm{SO} 2} / \mathrm{kg}_{\mathrm{F}} \\
\mathrm{V}_{\mathrm{N} 2}=(22,4 / 28) \mathrm{S}+0,79 \times \mathrm{V}_{\mathrm{aa}}=(22,4 / 28) 0,006+0,79 \\
\times 13,5=10,67 \mathrm{~m}^{3}{ }_{\mathrm{N} 2} / \mathrm{kg}_{\mathrm{F}} \\
\mathrm{V}_{\mathrm{O} 2}=0,21(\alpha-1) \mathrm{V}_{\mathrm{a}}=0,21(1,25-1) 10,8=0,567 \\
\mathrm{~m}^{3}{ }_{\mathrm{O} 2} / \mathrm{kg}_{\mathrm{F}} \\
\left.\mathrm{V}_{\mathrm{H} 2 \mathrm{O}}=(22,4 / 2) \mathrm{H}\right)+(22,4 / 18) \mathrm{W}=(22,4 / 2) 0,116+ \\
(22,4 / 18) 0=1,299 \mathrm{~m}^{3}{ }_{\mathrm{H} 2 \mathrm{O}} / \mathrm{kg}_{\mathrm{F}}
\end{gathered}
$$

i ukupni volumen dimnih plinova sa suviškom zraka jest:

$$
\mathrm{V}_{\mathrm{FG}}=14,1455 \mathrm{~m}_{\mathrm{FG}}^{3} / \mathrm{kg}_{\mathrm{F}}
$$


Udio svakog sastojka izražen kao postotak ukupnih vlažnog dimnih plinova:

$$
\begin{gathered}
\mathrm{CO}_{2}: 11,25 \% ; \mathrm{SO}_{2}: 0,12 \% ; \mathrm{N}_{2}: 75,43 \% ; \mathrm{O}_{2}: 4,02 \\
\% ; \mathrm{H}_{2} \mathrm{O}: 9,18 \% .
\end{gathered}
$$

Specifična toplina ispušnih plinova s temperaturom $t_{F G}$ $=221^{\circ} \mathrm{C}$ i postotak volumena dimnih plinova kao i specifična toplina svakog plina izračunavaju se prema izrazu (Bošnjaković, 1971.):

$$
\begin{aligned}
& c_{p F G}=c_{p ~ C O 2} c \% V_{c 02}+c_{p ~ S O 2} \times \% V_{\text {sO2 }}+c_{p ~ N 2} \times \% V_{N 2}+ \\
& c_{\mathrm{p} \mathrm{O} 2} \times \% \mathrm{~V}_{2}+\mathrm{c}_{\mathrm{pH} 2 \mathrm{O}} \times \% \mathrm{~V}_{\mathrm{H} 2 \mathrm{O}}=1,392 \mathrm{~kJ} / \mathrm{m}^{3} \mathrm{grad} \text {. }
\end{aligned}
$$

Energija koja se oslobađa pri potpunom izgaranju po jedinici mase goriva ili po jedinici proizvoda ovisi o ukupnom volumenu dimnih plinova, specifičnoj toplini i temperaturi dimnih plinova:

$$
\begin{aligned}
& q_{F G}=v_{F G} \times c_{p F G} \times t_{F G}=14,1455 \times 1,392 \times 221= \\
& \quad 4351,61 \mathrm{~kJ}_{F G} / k_{F} \\
& q_{F G P}=q_{F G} \times d_{F}=4351,61 \times 1,21=5265 \mathrm{~kJ}_{F G} / k_{P} .
\end{aligned}
$$

Volumen ispušnih plinova po jedinici proizvoda izbačen $\mathrm{u}$ okolinu s temperaturom $\mathrm{t}_{\mathrm{FG}}=221^{\circ} \mathrm{C}$ jest:

$$
V_{F G P}=V_{F G} \times d_{F}=14,1455 \times 1,21=17,11 \mathrm{~m}^{3}{ }_{F G} / k_{P} \text {. }
$$

\section{OPTIMIZACIJA UŠTEDE ENERGIJE U PROIZVODNJI POTPLATA ZA CIPELE}

\subsection{POVRAT TOPLINE PROCESNOGA KONDENZATA}

Povrat vrućega kondenzata u kotao odvija se radi uštede energije. Primjenom povratnoga kondenzata za zagrijavanje pojne vode potrebna je manja količina svježe vode, manja potrošnja goriva za proizvodnju pare iz tople vode umjesto hladne vode. Povrat kondenzata visoke čistoće, tj. destilirane vode smanjuje i troškove kemikalija i tretmana, kao i gubitke energije zbog propuhivanja kotla (Nautiyal, 2012.). U analiziranom tehnološkom procesu procesni se kondenzat vraća $u$ količini od $d_{C R}=14,170 \mathrm{~kg}_{C} / \mathrm{kg}_{\mathrm{p}} \mathrm{s}$ temperaturom od $t_{C}=121^{\circ} \mathrm{C}$ te miješa s pojnom vodom $\mathrm{u}$ količini od $\mathrm{d}_{\mathrm{w}}=0,700 \mathrm{~kg}_{\mathrm{w}} / \mathrm{kg}_{\mathrm{p}} \mathrm{s}$ temperaturom od $\mathrm{t}_{\mathrm{w}}=$ $25^{\circ} \mathrm{C}$.

S obzirom na adijabatski postupak miješanja, pojna će voda ući u kotao $s$ temperaturom:

$$
\begin{aligned}
t_{m}=\left(d_{C R} \times t_{c}+d_{w} t_{w}\right) / d_{s} & =(14,170 \times 121+0,700 \times \\
25) / 14,870 & =116,48^{\circ} \mathrm{C} .
\end{aligned}
$$

Potrošnja goriva izračunava se u skladu s jednadžbom energetske ravnoteže:

$$
\begin{gathered}
d_{F C}=d_{s}\left(h_{s}-h_{m}\right) / H_{L} \times \eta_{B}=14,870(2785-492) 41268 \\
\times 0,8=1,03 k_{F} / k_{P .} .
\end{gathered}
$$

Specifična potrošnja pare jest:

$$
d_{\mathrm{SPC}}=d_{\mathrm{S}} / \mathrm{d}_{\mathrm{FC}}=14,870 / 1,03=14,44 \mathrm{~kg}_{\mathrm{S}} / \mathrm{kg}_{\mathrm{P}} \text {. }
$$

Godišnja potrošnja jest:

$$
D_{F C Y}=d_{F} \times n=1,03 \times 2400 \times 625=1,545 \times 10^{6} \mathrm{~kg}_{\mathrm{F}}
$$

Toplina kondenzata za predgrijavanje pojne vode jest:

$Q_{C}=d_{C} \times h_{121}{ }^{0}=14,170 \times 507=7184,19 \mathrm{~kJ}_{\mathrm{C}} / \mathrm{kg}_{\mathrm{P}}$

Primjena povratnoga kondenzata u komparaciji $\mathrm{s}$ procesom bez povrata topline kondenzata pokazuje uštedu goriva od:

$$
\begin{gathered}
S=\left(d_{F}-d_{F C}\right) / d_{F}=(1,21-1,03) / 1,21=0,1487 \text { i. e. } \\
14,9 \% .
\end{gathered}
$$

Toplina kondenzata, koja se ispušta u okolinu, postaje:

$$
\mathrm{q}_{\mathrm{CH}}=\mathrm{d}_{\mathrm{CH}} \times \mathrm{h}_{121}=0,7 \times 507=354,9 \mathrm{~kJ}_{\mathrm{C}} / \mathbf{k g}_{\mathrm{P}}
$$

Dakle, toplinsko se onečišćenje smanjuje od 7539,1 $\mathrm{kJ} / \mathrm{kg}_{\mathrm{p}}$ do $354,9 \mathrm{~kJ} / \mathrm{kg}_{\mathrm{p}}$ ili 95,3\%.

$\mathrm{U}$ ovom radu analizira se volumen dimnih plinova po jedinici proizvoda koji se odbacuje u atmosferu $s$ temperaturom $\mathrm{t}_{\mathrm{FG}}=221^{\circ} \mathrm{C}$ iz:

$$
V_{F G C}=V_{F G} \times d_{F C}=14,1455 \times 1,03=14,57 \mathrm{~m}^{3}{ }_{F G} / k_{P} \text {. }
$$

Volumen ispušnih plinova smanjuje se od 17,11 $\mathrm{m}^{3}{ }_{\mathrm{FG}} / \mathrm{kg}_{\mathrm{P}}$ do $14,57 \mathrm{~m}_{\mathrm{FG}}^{3} / \mathrm{kg}_{\mathrm{P}}$ ili $14,8 \%$ (Špelić et al., 2019.)

\subsection{PREDGRIJAVANJE POJNE VODE DIMNIM PLINOVIMA}

Sažetak ulaznih podataka:

- učinkovitost ekonomajzera $\eta_{E}=80 \%$

- temperatura vode na ulazu u ekonomajzer $t_{w_{e i}}=$ $116,78^{\circ} \mathrm{C}$

- volumen ispušnih dimnih plinova $V_{F G}=14,1455$ $\mathrm{m}_{\mathrm{FG}}^{3} / \mathrm{kg}_{\mathrm{F}}$

- temperatura dimnih plinova na ulazu u ekonomajzer $\mathrm{t}_{\mathrm{FGEi}}=221^{\circ} \mathrm{C}$

- specifična potrošnja pare $d_{S P}=14,44 \mathrm{~kg}_{\mathrm{S}} / \mathrm{kg}_{\mathrm{F}}$

- specifična toplina vode $\mathrm{c}_{\mathrm{pH} 2 \mathrm{O}}=4,187 \mathrm{~kJ} / \mathrm{kg} \mathrm{K}$

- specifična toplina dimnih plinova $\mathrm{C}_{\mathrm{pFG}}=1,392 \mathrm{~kJ}_{\mathrm{FG}} / \mathrm{m}^{3}$ deg

- masa suhe zasićene pare $d_{\mathrm{s}}=14,870 \mathrm{~kg}_{\mathrm{s}} / \mathrm{kg}_{\mathrm{P}}$

- entalpija pare $h_{s}=2785 \mathrm{~kJ} / \mathrm{kg}$

- donja toplinska vrijednost goriva $H_{L}=41268 \mathrm{~kJ} / \mathrm{kg}_{\mathrm{F}}$

Hladna voda temperature $t_{w E i}=116,78^{\circ} \mathrm{C}$ ulazi $u$ ekonomajzer gdje se zagrijava $s$ pomoću dimnih plinova u količini $\mathrm{V}_{\mathrm{FG}}=14,1455 \mathrm{~m}_{\mathrm{FG}}^{3} / \mathrm{kg}_{\mathrm{F}} \mathrm{s}$ ulaznom temperaturom $t_{\mathrm{FGEi}}=221^{\circ} \mathrm{C}$. Specifična potrošnja pare jest $d_{S P}=14,44 \mathrm{~kg}_{\mathrm{S}} / \mathrm{kg}_{\mathrm{F}}$, specifična toplina vode jest $\mathrm{C}_{\mathrm{p}}$ ${ }_{\text {H2O }}=4,187 \mathrm{~kJ} / \mathrm{kg} \mathrm{K}$ i specifična toplina dimnih plinova jest $C_{p F G}=1,392 \quad \mathrm{~kJ}_{F G} / \mathrm{m}^{3}$ deg, koje su prethodno izračunate.

Temperatura vode na izlazu iz ekonomajzera $\left(t_{w_{E 0}}\right)$ računa se prema jednadžbi energetske ravnoteže:

$$
\begin{aligned}
& V_{F^{*}} c_{p F G^{*}}\left(t_{F G E i}-t_{w_{E i}}\right) \eta_{E}=d_{S P P^{*}} c_{p H 2 O^{*}}\left(t_{W_{E O}}-t_{W_{E i}}\right)
\end{aligned}
$$

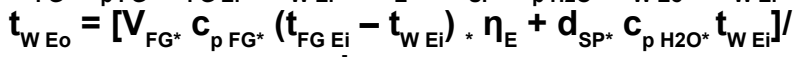

$$
\begin{aligned}
& d_{\mathrm{SP}^{*}} \mathrm{c}_{\mathrm{p} \mathrm{H} 2 \mathrm{O}} \\
& t_{w_{E o}}=143,71^{\circ} \mathrm{C}
\end{aligned}
$$

Temperatura dimnih plinova na izlazu iz ekonomajzera $\left(\mathrm{t}_{\mathrm{FG} \mathrm{E} \mathrm{E}}\right)$ računa se prema izrazu: 


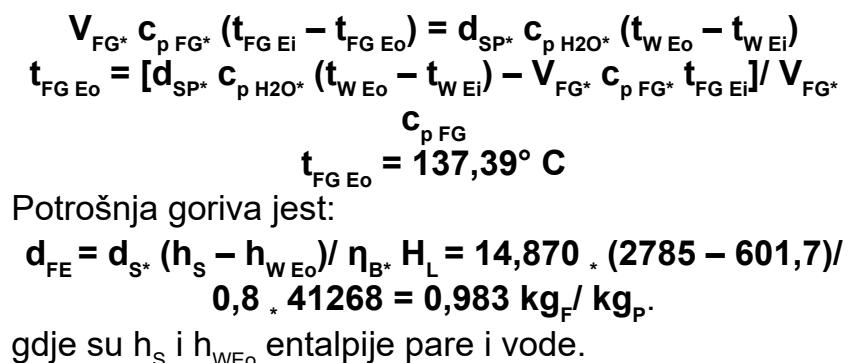

Usporedba procesa s povratom topline dimnih plinova i bez njega pokazuje uštedu goriva:

$$
\begin{gathered}
S_{1}=\left(d_{F}-d_{F E}\right) / d_{F}=(1,21-0,983) / 1,21=0,1876 \text { i. e. } \\
18,76 \% .
\end{gathered}
$$

Količina dimnih plinova odbačenih $u$ atmosferu jest:

$$
V_{F G E}=V_{F^{*}} d_{F E}=14,1455 * 0,983=13,90 \mathrm{~m}^{3}{ }_{F G} / k_{P} \text {. }
$$

\section{ZAKLJUČAK}

Izračunavanje uštede energije u pogonima za preradu gume vrlo je važno jer sintetička guma čini većinu proizvodnje gume. Većina potplata danas je napravljena od etilen vinil acetata (EVA). U ovom radu analiziran je potencijal uštede energije primjenom procesa povratnoga kondenzata i predgrijavanja pojne vode primjenom povrata topline dimnih plinova u procesu proizvodnje EVA potplata. Uštede energije vidljive su kroz manju potrošnju vode, znatnu uštedu goriva i manju potrošnju kemikalija. Vraćanjem kondenzata topline $\mathrm{u}$ kotao rezultira uštedom goriva od $14,9 \%$, toplinsko onečišćenje se smanjuje $95,3 \%$, dok se volumen dimnih plinova smanjuje sa 17,11 $\mathrm{m}_{\mathrm{FG}}^{3} / \mathrm{kg}_{\mathrm{NEC}}$ na $14,57 \mathrm{~m}^{3} \mathrm{FG} / \mathrm{kg}_{\mathrm{NEC}}$ ili $14,8 \%$. Također, primjenom povrata topline dimnih plinova za predgrijavanje pojne vode može se poboljšati tehnološki proces. Primjenom prikazane metode primjenom dimnih plinova povećava se temperatura vode na ulazu u kotao.

\section{ZAHVALA}

Ovaj je rad financiran projektom HRZZ IP-06-2016 5278: Udobnost i antimikrobna svojstva tekstila i obuće (ComforMicrobTexFoot).

\section{REFERENCE}

[1] Landrock, Arthur H. 1995. Handbook of plastic foams types, properties, manufacture and applications. Noyes Publications.

[2] Groover, M. P. 2010. Fundamentals of Modern Manufacturing: Materials, Processes and Systems. $4^{\text {th }}$ edition, John Wiley \& Sons Inc.

[3] Karkalića, R. M.; Radulović, J. R.; Jovanović, D. B. 2017. Characteristics of polyurethane and elastomer parts for shoe industry produced by liquid injection molding technology. Vojnotehnički glasnik, vol. 65 , br. 4, str. 948 967 http://dx.doi.org/10.5937/vojtehg65-10543.

[4] Chung, T. C. Mike. 2002. Functionalization of Polyolefins. $1^{\text {st }}$ edition, Academic Press.

[5] Brito e Dias, R.; Coto, N. P.; Batalha, G. F.; Driemeier, L.
2018. Systematic Study of Ethylene-Vinyl Acetate (EVA) in the Manufacturing of Protector Devices for the Orofacial System, Chapter 14, Biomaterials in Regenerative Medicine, ISBN: 978-953-51-3777-1.

[6] Shi, X. M.; Zhang, J.; Jin, J.; Chen, S. J. 2008. Nonisothermal crystallization and melting of ethylene-vinyl acetate copolymers with different vinyl acetate contents. eXPRESS Polymer Letters Vol. 2, No. 9, 623 - 629, DOI: 10.3144/expresspolymlett.2008.75

[7] Jeng, Y. -R.; Liu D. -S. and Yau, H. -T. 2012. Designing Experimental Methods to Predict the Expansion Ratio of EVA Foam Material and Using Finite Element Simulation to Estimate the Shoe Expansion Shape. Materials Transactions, Vol. 53, No. 9, pp. 1685 to 1688.

[8] Nautiyal, O. H. 2012. Molding of EVA Soles Using Expanding and Reducing Agents. International Journal of Engineering Science and Technology (IJEST), Vol. 4 No. 07, pp. $3050-3058$.

[9] López, L. C. 2014. Polymer injection moulding for shoe soles production. M. Sc. Thesis, Vilnius Gediminas technical university faculty of mechanics.

[10] Ferreir, E. J.; Dias, M. M.; Schneider, E. L. 2018. Analysis of Non-Uniform Expansion Behavior of Injected EVA. Academ J Polym Sci.; 1(4): 555569.

[11] Mihelić-Bogdanić, A.; Budin, R. 2008. Investigation on energy conservation in thermoplastics production, Energy conversion and management, 49, 8; 2200 2206, doi:10.1016/j.enconman.01.028

[12] Eastop, T. D.; McConkey, A. 1994. Applied Thermodynamics for Engineering Technologists. $5^{\text {th }}$ ed. New York: Longman Scientific \& Technical, John Wiley \& Sons.

[13] Bošnjaković, F. 1971. Technische Thermodynamik. Dresden: Verlag T. Steinkopff.

[14] Wang, L.; Hong, Y.; Li, J. X. 2012. Durability of running shoes with ethylene vinyl acetate or polyurethane midsoles. Journal of Sports Sciences, 30, 16, 1787 1792, doi:10.1080/02640414.2012.723819

[15] Lopes, D.; Ferreira, M. J.; Russo, R.; Dias, J. M. 2015. Natural and synthetic rubber / waste - EVA (EthyleneVinyl Acetate) composites for sustainable application in the footwear industry. Journal of Cleaner Production, $\quad 92, \quad 230 \quad$ - $\quad 236$, http://dx.doi.org/10.1016/j.jclepro.2014.12.063

[16] Fuss, F. K.; Subic, A.; Strangwood, M.; Mehta, R. 2014. Routledge Handbook of Sports Technology and Engineering. Routledge, Taylor and Francis, ISBN 9780415580458

[17] Špelić, I.; Mihelić-Bogdanić, A.; Budin, R. Energy savings in shoe sole production process. In: Book of Proceedings of the 12th International ScientificProfessional Symposium Textile Science and Economy, French-Croatian Forum, 23. do 24. siječnja 2019. Zagreb. Hrvatska, pp. $245-254$. 